\title{
Dental Root Channel Treatment of the Mandibular First Premolar with Type IV Vertucci Channel Morphology
}

\author{
Bilge Ozcan ${ }^{1}$, Bade Sonat ${ }^{2}$ \\ ${ }^{1}$ Turkish Ministry of Health Mamak Oral and Dental Health Center, Ankara, Turkey \\ ${ }^{2}$ Ankara University, Faculty of Dentistry, Department of Endodontics Ankara, Turkey \\ *Corresponding Author: Bilge Ozcan, Turkish Ministry of Health Mamak Oral and Dental Health \\ Center, Ankara, Turkey.
}

\begin{abstract}
For a successful root canal treatment, ideally performing biomechanical preparation in root canals and applying a hermetic root canal filling constitute the basic principles of endodontic treatment. The root canal form frequently seen in mandibular premolars is Vertucci Type I. The purpose of this case report is to demonstrate the endodontic treatment of a bichannel mandibular premolar tooth. Composite restoration was observed clinically in the mandibular left first premolar tooth. Radiographically, periapical tissues were healthy. As a result of the examinations and pain assessment, the tooth was diagnosed with irreversible pulpitis. The second canal in the lingual was found in the tooth whose endodontic treatment was initiated.
\end{abstract}

The treatment of the tooth prepared using rotary systems was completed with angled guttas and Sealapex root canal sealer.

Keywords: mandibular first premolar, Vertucci, anatomical variation

\section{INTRODUCTION}

For a successful root canal treatment, ideally performing biomechanical preparation in root canals and applying a hermetic root canal filling constitute the basic principles of endodontic treatment. In order for all these applications to be performed, the entrance to the root canal system must be performed correctly and in accordance with the anatomy of the tooth $[1,2]$. The root canal form frequently seen in mandibular premolars is Vertucci Type I. Rate of variation in root canals is higher in mandibular first premolar teeth compared to second premolar teeth. Vertucci determined the probability of having a second canal at a rate of $30 \%$ in first premolar teeth and $25 \%$ in second premolar teeth $[2,3]$.

\section{Case Report}

A 16-year-old female patient applied to Ankara University Faculty of Dentistry Endodontics clinic with a complaint of pain. No systemic disease was found in the medical history taken from the patient. As a result of the clinical examination, it was determined that there was a composite filling restoration made about a month ago in the lower left first premolar tooth. In clinical tests, percussion, palpation and mobility findings were not observed. No swelling was found in the soft tissue evaluation other than hard tissue evaluation. In the radiographic films taken from the patient, no radiolucency was found in the periapical region of the relevant tooth, and continuity of the lamina dural was observed (Figure 1 and Figure 2).

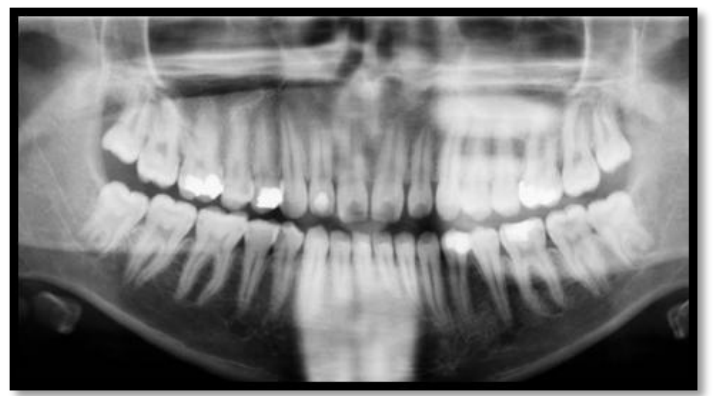

Figure1. Radiographic film of thepatient (general view)

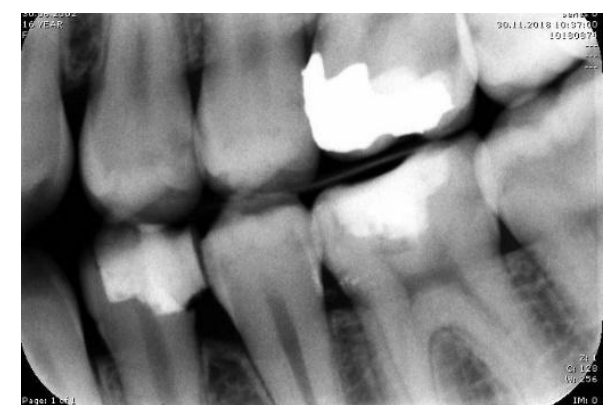

Figure2. Radiographic film of thepatient (focusedview) 
As a result of all these evaluations, the tooth was diagnosed with irreversible pulpitis and the root canal treatment procedure was decided. The old restoration was removed under local anesthesia (Ultraca D-SA, Aventis Pharma, Istanbul, Turkey) and endodontic access cavity was opened. Radiographs were taken by inserting a rubber-dam on the tooth with two different canal mouths (Figure 3), K-type files numbered \# 10, and determining the canal length (Figure 4).

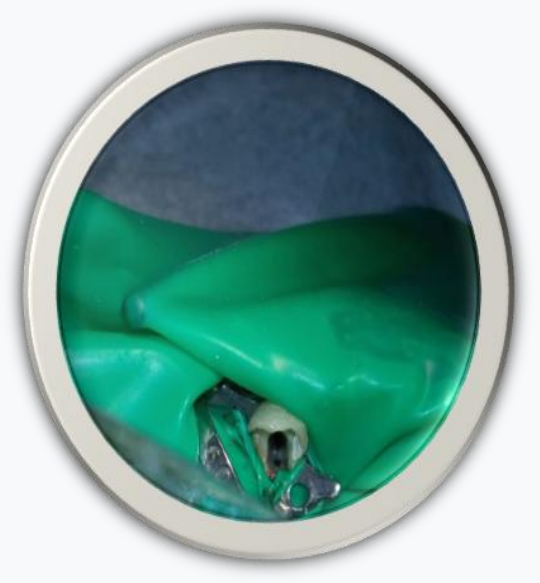

Figure3. Attachment of a rubber-dam to the tooth with two separate canal mouths

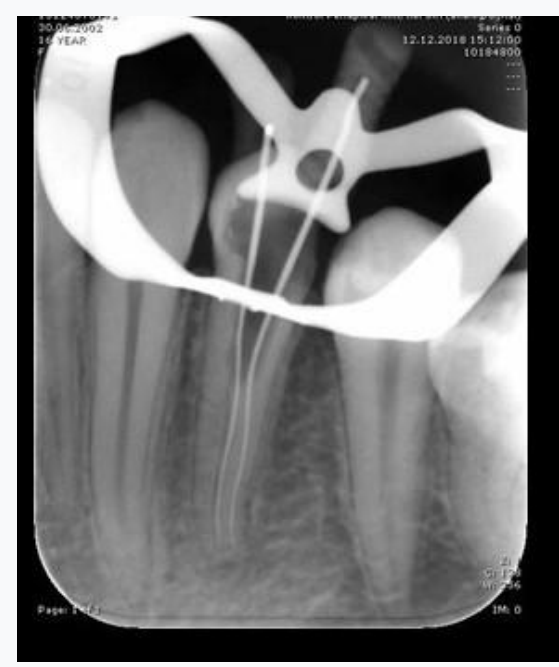

Figure4. Determining of canallength

After the root canals were extirpated, preparation was started using a rotary system. Root canals were irrigated with $2.5 \%$ sodium hypochlorite solution for each file change. ProTaper (Universal, Dentsply Maillefer, Switzerland) file system was used as S1, S2, F1 and F2, respectively. Saline was used as the final wash irrigation and the channels were dried with a sterile paper point. Root canal filling was performed with F2 angled gutta (Dentslay Maillefer, Switzerland) and Sealepex (Kerr, Italy) root canal filling sealer (Figure 5).

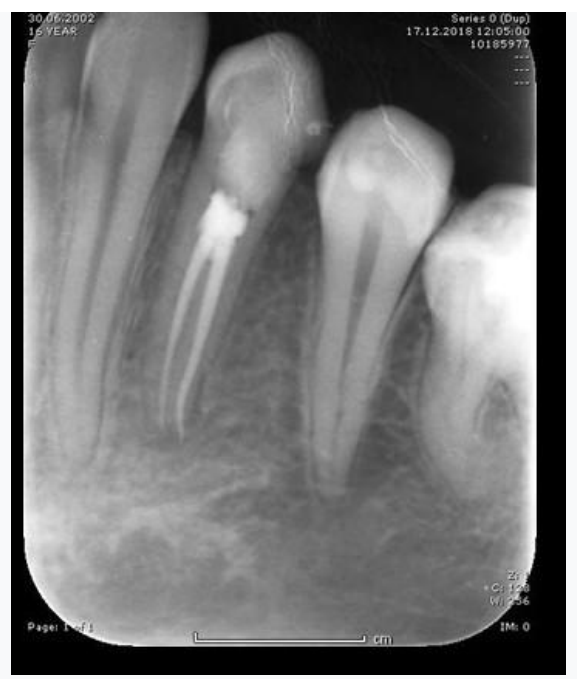

Figure5. Root canal filling with F2 angled gutta (DentslayMaillefer, Switzerland) and Sealepex (Kerr, Italy) root canal sealer

If a sudden narrowing or disappearance of the pulp chamber is observed on the radiography, the root canal may be divided into two in that area [2,4,5]. Mandibular premolar teeth are typically among the most difficult teeth to treat due to the overlooked differences in root canal morphology. It has been found that $22.7 \%$ of mandibular first premolar teeth and $16 \%$ of second premolar teeth could have more than one canal [6].In a study conducted on the Turkish population, the rate of encountering more than one canal in mandibular premolar teeth was found to be $27.76 \%$ [7]. The rate of additional channels reaching the apex through more than one foramen was determined to be $23.49 \%$ [7]. Anatomical variations in mandibular premolar teeth have been demonstrated in several studies $[8,9]$.

\section{DISCUSSION}

A successful root canal treatment is possible with clinical and radiographic evaluations as well as the detection of anatomical variations and their correct treatment $[4,10]$. The different positioning of the canal mouths in the entrance cavity suggests that there may be more channels [11]. In general, if the diameter of the central part of the root is equal to or greater than the diameter of the tooth crown on the radiography, root channel variations should be suspected $[11,12]$. In such cases, the localization of the channels can be evaluated with radiographs taken from different angles. For a successful endodontic treatment, the physician should make radiographic and clinical evaluations considering the frequency of variations in addition to root canal morphology. 
Dental Root Channel Treatment of the Mandibular First Premolar with Type IV Vertucci Channel Morphology

\section{REFERENCES}

[1] Chan K, Yew SC, Chao SY (1992) Mandibular premolar with three root canals-two case reports. Int Endod J 25(5): 261-264.

[2] Vertucci FJ (1984) Root canal anatomy of the human permanent teeth. Oral Surg Oral Med Oral Pathol 58(5): 589-599.

[3] Vertucci FJ (1978) Root canal morphology of mandibular premolars. J AmDentAssoc 97(1): 47-50.

[4] Pineda F, Kuttler Y (1972) Mesiodistal and buccolingual roentgenographic investigation of 7,275 rootcanals. Oral Surg Oral Med Oral Pathol 33(1): 101-110.

[5] Miyoshi S, Fujiwara J, TsujiY Nakata T, Yamamoto K (1977) Bifurcated root canals and crown diameter. J DentRes 56(11): 1425.

[6] Zillich R, Dowson J (1973) Root canal morphology of mandibular first and second premolars. Oral Surg Oral Med Oral Pathol 36 (5): 738-744.

[7] Kartal N, Yanikoğlu F (1992) The incidence of mandibular premolars withmo rethan one root canal in a Turkish population .J Marmara UnivDentFac 1(3) :203-210.

[8] Green D (1973) Doublecanals in singleroots. Oral Surg Oral Med Oral Pathol35(5):689-696.

[9] England MC Jr, Hartwell GR, Lance JR (1991) Detection and treatment of multiple canals in mandibular premolars. J Endod 17(4): 174-178.

[10] ElDeeb ME (1982) Three root canals in mandibular second premolars: literature review and a case report. J Endod8(8): 376-377.

[11] Trope M, Elfenbein L, Tronstad L (1986) Mandibular premolars with more than one root canal in differentrace groups. J Endod 12(8): 343-345.

[12] Hession RW (1977) Endodontic morphology. II. A radiographic analysis. Oral Surg Oral Med Oral Pathol 44(4): 610-620.

Citation: Bilge Ozcan \& Bade Sonat, "Dental Root Channel Treatment of the Mandibular First Premolar with Type IV Vertucci Channel Morphology”, International Journal of Research Studies in Medical and Health Sciences. 2020; 5(12): 33-35.

Copyright: (C) 2020 Bilge Ozcan \& Bade Sonat, This is an open-access article distributed under the terms of the Creative Commons Attribution License, which permits unrestricted use, distribution, and reproduction in any medium, provided the original author and source are credited. 